\title{
The State of the Field: Political Science and Chinese Political Studies
}

\author{
Sujian Guo • Jean-Marc F. Blanchard
}

Published online: 9 June 2009

(C) Journal of Chinese Political Science/Association of Chinese Political Science 2009

The Journal of Chinese Political Science (JCPS) is publishing a series of special issues, containing retrospective and prospective papers on the state of Chinese political studies, past, present and future. We call upon China scholars worldwide to contribute to these important special issues which will have a significant impact on the intellectual development of the field. Our goal is to disseminate scholarship that can shed light on the ever changing field of Chinese political studies, provide valuable material for scholar teachers and researchers of Chinese politics, and highlight the achievements, problems and issues, and directions of this field.

We have witnessed the substantial transformation of China studies, particularly Chinese political studies, in the past 30 years due to changes in China and its rising status in the world as well as changes in our ways of conducting research. As area studies specialists, we are no longer "isolated" from the larger disciplines of Political Science and International Relations (IR) but an integral part of them. A simple survey of the JCPS and other journals reveals that we have applied theories and methods from these larger disciplines to Chinese political studies and that we have sought to meet the standards of scientific research and theoretical relevance in the two disciplines. The scholarship we produce today has advanced far beyond the days of classic Sinology. However, theoretical and methodological approaches in Chinese political studies are very diverse, and substantive issues in various Chinese contexts are being studied from a broader comparative perspective. As Lynn T. White points out in his paper, "Chinese and Asian comparative research can help reverse the methodological narrowness that obscures much actual politics in the world from being studied circumspectly."

Scholars and students in our field still vividly remember texts used in graduate school and innumerable papers published by first rate comparativists such as Sydney Verba, Arendt Lijphart, David Collier, James Mahon, Giovanni Satori, Gary King, David Easton, and many others. All of them have had a great impact on how we

S. Guo $(\bowtie) \cdot$ J.-M. F. Blanchard

Center for US-China Policy Studies, San Francisco State University, 1600 Holloway Ave. HSS 263,

San Francisco, CA 94132-4155, USA

e-mail: sguo@sfsu.edu 
study China and Chinese politics. In the area of IR, many IR theorists, such as Hans Morgenthau, Kenneth Waltz, Robert Keohane, Robert Gilpin, Joseph Nye, Robert Jervis, Stephen Krasner, Francis Fukuyama, and others have influenced how we study China and its foreign policy behavior. It is time to examine and evaluate the state of Chinese political studies-i.e., its accomplishments, problems, and directions - and we hope you will be part of this important endeavor.

This issue is the first special issue of the series: "The State of the Field: Political Science and Chinese Political Studies." The four essays in this special issue specifically examine the state of the field with respect to various thematic topics, and evaluate the field's intellectual development and assess how Chinese political studies links with the broader discipline of political science. Lynn T. White provides a wide ranging survey of Chinese political studies. Peter Moody considers the treatment of culture in field of Chinese political studies. Yang Guangbin and Li Miao reflect upon Western Chinese political studies/political science and the development of political theories in China. Along similar lines, Jing Yuejin and Wang Guoqin look at Western Chinese political studies/political science, albeit focusing on methodology and the influence of Western methodological approaches on Chinese political science.

In his essay, Lynne T. White does yeoman's work in tracing the diverse ways in which China specialists have grappled with the complexities of political legitimacy in the Chinese context. He also sheds light on the way politico-economy minded China specialists have dealt with the political variables shaping economics and viceversa. Moreover, White summarizes well the breadth of themes relating to political leadership that have engaged scholars as well as the myriad of approaches they have used to delve into this subject. Other themes attracting White's attention include the financial, intellectual, and library resources sustaining the field as well as the increasing emphasis on (requirement for?) statistical analyses in the field, a trend which concerns him. White believes that the field of Chinese political studies can retain its vitality if it avoids excessive reliance on methodological individualism since such an approach cannot illuminate preferences as well as if it there remain adequate opportunities for Chinese scholars to contribute to the field of Chinese political studies.

Peter R. Moody directs our attention to the use, abuse, and neglect of political culture in the field of Chinese political studies. He opines that the field now seems to be moving away from paying attention to culture as an explanatory factor. Certainly, there are challenges in employing this factor, but for Moody it is equally problematic to neglect it. Despite some early dismissals of the continuing relevance of traditional culture after the Communist revolution, Moody points out that analysts found it hard to escape the fact that traditional culture remained part of the post-1949 political discourse. He reports, too, that older studies seemed overly reliant on psychology to explain the continuing relevance of traditional culture in China, though situational factors provided a more compelling explanation. Moody sees value in treating political culture as a structural variable, but acknowledges it cannot offer pinpoint predictions. Regardless, it can be a useful tool for analyzing continuity, for conducting comparative analysis, and for analyzing political processes. Moody's closing advice is that we must think about political culture if we are to grasp the values that political actor seek to maximize. 
Yang Guangbin and Li Miao chronicle the development of political studies in China. They write that an infusion of western political works and the training of thousands of Chinese scholars in western universities supplied the basis for a new kind of Chinese political science that stressed interest group and institutional analysis. While some Chinese researchers initially embraced Western academic concepts like "authoritarianism" to describe Chinese domestic politics and "electoral democracy" as the standard for democracy, other scholars began to take a more critical stance towards the crude application of such concepts to the Chinese context. Nevertheless, Western approaches such as class analysis and historical institutionalism have left an enduring footprint on political studies in China. Still, Chinese researchers have developed their own lenses such as the "political process approach" and "party-centered approach" to better capture the special features of Chinese political reform as well as the unique role that the Chinese Communist Party plays in the modernization of the state. Yang and Li's final note is that a more sensitive application of terminology and models may lead to improved academic discourse.

In their contribution, Jing Yuejin and Wang Guoqin also look at the development of political studies in China, focusing on methodology. They report that, for the most part, Chinese political studies have tracked the Western preference for empirical analysis (e.g., pluralism, corporatism, and rational choice theory) as opposed to interpretative analysis (e.g., interpretive theory and feminism). Since the 1990s, rationalism and new institutionalism have gained great traction. In contrast to Yang and Li's essay, Jing and Wang contend that new institutionalism from economics has been more popular than historical institutionalism due to China's focus on economic transformation and the fact that new institutionalism seems more relevant in an evolving context than historical institutionalism. As for rational choice theory, Yang and $\mathrm{Li}$ provide intriguing data showing that its high profile relates more to frequent general treatments than specific applications. Recognizing the value of Western methodologies, Jing and Wang still contend that Chinese political science needs to move in the direction of constructing analytical categories, methods, and analytical frameworks based on the Chinese experience. 